\title{
IMPLEMENTASI TEXT MINING UNTUK ANALISIS OPINI MASYARAKAT TERHADAP KINERJA LAYANAN TRANSPORTASI ONLINE DENGAN ANALISIS FAKTOR
}

\author{
Immanuel Olive Djaja Putra ${ }^{1}$, Kestrilia Rega Prilianti ${ }^{2}$, Paulus Lucky \\ Tirma Irawan ${ }^{3}$ \\ ${ }^{1,2,3}$ Program Studi Teknik Informatika, Fakultas Sains dan Teknologi,Universitas Ma \\ Chung Villa Puncak Tidar Blok N-01, Tidar, Malang

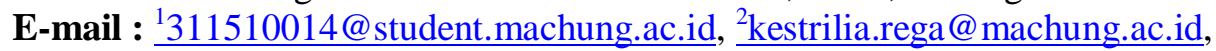 \\ 3paulus.lucky@machung.ac.id
}

\begin{abstract}
ABSTRAK
Sistem transportasi umum saat ini berbasis aplikasi yang terhubung dengan koneksi internet sehingga dapat disebut juga dengan transportasi online. Grab dan Gojek merupakan penyedia jasa transportasi online yang ingin memberikan pelayanan kepada pengguna dengan baik. Beberapa pengguna memberikan tanggapan tentang layanan yang diberikan, pengalaman, kritik maupun saran bagi kedua perusahaan tersebut melalui Twitter. Pada penelitian ini dibuat sebuah aplikasi untuk menganalisis opini masyarakat terhadap layanan Grab dan Gojek dengan implementasi text mining menggunakan algoritma Naïve Bayes Classifier yang digunakan untuk mengklasifikasi tweet ke dalam kelas sentimen positif atau sentimen negatif dan Principal Component Analysis (PCA) yang digunakan untuk menentukan faktor dari setiap sentimen yang telah divalidasi. Data diperoleh melalui Twitter dengan kata kunci "grab" dan "gojek". Dari hasil penelitian didapatkan hasil akurasi klasifikasi data uji sentimen pada objek Grab adalah 74,34\% dengan jumlah data 152 tweet dan data latih 597 tweet, sedangkan hasil akurasi klasifikasi data uji pada objek Gojek adalah 68,84\% dengan jumlah data 565 tweet dan data latih 2249 tweet. Hasil akurasi diperoleh dengan menggunakan nilai threshold sebesar 1.1. Setiap kelas sentimen dilakukan analisis faktor yang kemudian pada Grab diperoleh 6 faktor positif dan 5 faktor negatif, sedangkan pada Gojek diperoleh 8 faktor positif dan 6 faktor negatif. Setiap faktor yang diperoleh dilakukan interpretasi dan kemudian dilakukan validasi oleh pakar.
\end{abstract}

Kata kunci : Analisis Faktor, Analisis Sentimen, Nä̈ve Bayes Classifier, Principal Component Analysis, Text Mining.

\begin{abstract}
The current public transportation system is based on an application that is connected to an internet connection so that it can be called online transportation. Grab and Gojek are providers of online transportation services who want to provide good services to users. Some users provide feedback about the services provided, experience, criticism and suggestions for the two companies via Twitter.In this study an application was made to analyze public opinion on Grab and Gojek services with the implementation of text mining using the Nä̈ve Bayes Classifier algorithm which is used to classify tweets into a class of positive sentiments or negative sentiments and Principal Component Analysis (PCA) used to determine factors of every sentiment that has been validated. Data is obtained via Twitter with the keywords "grab" and "gojek".The results showed that the accuracy of the classification of sentiment test data on Grab objects was $74.34 \%$ with 152 data tweets and 597 tweets of training data, while the accuracy of test data classification on Gojek objects was $68.84 \%$ with 565 tweets and 2249 tweets of data training data. Accuracy results are obtained by using a threshold value of 1.1. Each sentiment class was analyzed by factors which then in Grab obtained 6 positive factors and 5 negative factors, while in Gojek 8 positive factors and 6 negative factors were obtained. Every factor obtained is interpreted and then validated by experts.
\end{abstract}

Keywords: Factor Analysis, Naïve Bayes Classifier, Principal Component Analysis, Sentiment Analysis, Text Mining. 


\section{PENDAHULUAN}

Salah satu sarana transportasi yang sering digunakan adalah angkutan umum. Mengikuti perkembangan teknologi yang semakin maju, transportasi umum berkembang dengan pesat. Sistem transportasi umum saat ini ada yang berbasis aplikasi yang terhubung dengan koneksi internet sehingga dapat disebut juga dengan transportasi online. Di Indonesia terdapat dua penyedia jasa transportasi online, yaitu Grab dan Gojek. Berbagai macam layanan bahkan promosi diberikan kepada pengguna jasa transportasi online tersebut namun layanan yang disediakan juga tidak selalu sempurna dan tetap perlu adanya penyempurnaan. Oleh karena itu, tanggapan dari pengguna sangat diperlukan untuk memperbaiki layanan yang telah disediakan.

Beberapa pengguna memberikan tanggapan tentang layanan yang diberikan, pengalaman, kritik maupun saran bagi kedua perusahaan tersebut melalui media sosial salah satunya adalah Twitter. Media sosial merupakan media online yang digunakan sebagai kesempatan untuk berinteraksi dan memprersentasikan diri, baik secara langsung maupun tidak langsung dengan masyarakat yang mendorong nilai dari user-generated dan sudut pandang dengan orang lain [1]. Melakukan analisis opini masyarakat tentang keunggulan dan kekurangan terhadap kinerja layanan Grab dan Gojek pada media sosial secara manual memerlukan waktu dan tenaga yang banyak sehingga perlu dilakukan penerapan text mining untuk menganalisis opini masyarakat terhadap kinerja layanan transportasi online dengan data yang diperoleh dari Twitter menggunakan Twitter API. Kemudian data tersebut diolah menggunakan algoritma Naïve Bayes Classifier (NBC) untuk mengklasifikasi kelas sentimen. Setelah data terklasifikasi ke dalam kelas sentimen positif dan negatif, dilakukan analisis faktor menggunakan metode Principal Component Analysis (PCA).
Penelitian serupa telah dilakukan penerapan text mining untuk klasifikasi sentimen menggunakan algoritma NBC terhadap layanan dari Grab dan Gojek [2] dan layanan situs belanja online [3]. Pada penelitan ini tidak berhenti sampai tahap klasifikasi saja namun dilakukan hingga analisis faktor.

Tujuan dilakukan penelitan ini adalah mengembangkan aplikasi untuk analisis opini masyarakat terhadap keunggulan dan kekurangan dari layanan Gojek dan Grab dengan implementasi text mining menggunakan algoritma Naïve Bayes dan Analisis Faktor. Batasan masalah pada penelitian ini adalah analisis opini masyarakat terhadap kinerja layanan Gojek dan Grab menggunakan klasifikasi sentimen dan ekstrasi variable yang menentukan sentimen positif dan negatif, data yang diambil melalui Twitter berupa tweet pengguna yang berada di Indonesia, dan analisis menggunakan bahasa pemrograman Python yang kemudian diimplementasi ke dalam bentuk website.

\section{METODE}

Terdapat enam tahapan pada penelitian ini, yaitu analisis masalah, pengumpulan data, desain sistem, pengembangan aplikasi, proses pengujian dan simpulan analisis faktor. Penjelasan setiap tahap adalah sebagai berikut.

\section{Analisis Masalah}

Pada tahap ini diketahui bahwa kualitas layanan menjadi salah satu daya tarik bagi masyarakat untuk menilai baik atau buruknya penyedia jasa, begitu pula dalam bidang transportasi online. Komentar dari pengguna berupa kritik atau saran pun seringkali dibagikan melalui media sosial, salah satunya adalah Twitter.

Analisis sentimen masyarakat terhadap Gojek dan Grab secara manual membutuhkan banyak waktu dan tenaga yang dikeluarkan karena informasi yang terdapat media sosial bergerak dengan cepat, maka diperlukan teknik analisis sentimen secara otomatis agar dapat mempemudah penyedia jasa untuk 
memperbaiki maupun mengembangkan kualitas layanannya.

\section{Pengumpulan Data}

Pengumpulan data tweet pada penelitian ini dilakukan dengan cara mengambil data berupa tweet tentang Gojek dan Grab menggunakan Twitter API. Data yang diperoleh kemudian diklasifikasi secara manual ke dalam kelas sentimen positif dan sentimen negatif. Jumlah data hasil dari klasifikasi manual tersebut dibagi manjadi data uji sebanyak $20 \%$ dan data latih sebanyak $80 \%$. Pembagian data ke dalam data uji dan data latih dipilih secara acak.

\section{Desain Sistem}

Sistem pada penelitan ini sibuat menggunakan Python yang digunakan untuk melakukan text mining, analisis sentimen, dan analisis faktor. Pembuatan halaman antarmuka web menggunakan framework Flask.

Terdapat dua tahap text mining yaitu preprocessing yang digunakan sebagai penyempurnaan data mentah agar menjadi data yang lebih terstruktur dengan cara menghilangkan gangguangangguan pada data dan seleksi fitur yang digunakan untuk menghapus kata yang memiliki frekuensi kurang batas minimal yang ditentukan.

Tahap preprocessing terdiri dari proses mengubah semua huruf pada data menjadi huruf kecil, menghapus link, mention dan karakter yang bukan merupakah huruf (case folding), memecah teks menurut kata penyusunnya (tokenizing), menghapus kata-kata yang tidak penting berdasarkan data pada stopword (filtering), dan mengubah kata imbuhan menjadi kata dasar (stemming).

Kemudian dari hasil tahap preprocessing tersebut disimpan ke dalam tabel Document Term Matrix (DTM). Kolom dari setiap matriks tersebut berisi term atau kata yang diperoleh dari tahap preprocessing dan setiap barisnya berisi tweet. Nilai yang ada pada tabel merupakan frekuensi kemunculan kata dalam tweet dengan kata yang sudah diperoleh. Contoh struktur tabel Documen Term Matrix dapat dilihat pada tabel 1.
Tabel 1 Document Term Matrix

\begin{tabular}{|c|c|c|c|c|}
\hline Tweet & $\begin{array}{c}\text { Kata } \\
1\end{array}$ & $\begin{array}{c}\text { Kata } \\
2\end{array}$ & $\begin{array}{c}\text { Kata } \\
\ldots\end{array}$ & $\begin{array}{c}\text { Kata } \\
\mathrm{n}\end{array}$ \\
\hline Tweet 1 & 0 & 5 & $\ldots$ & 4 \\
\hline Tweet 2 & 1 & 1 & $\ldots$ & 2 \\
\hline$\cdots$ & $\cdots$ & $\cdots$ & $\cdots$ & $\cdots$ \\
\hline Tweet $\mathrm{n}$ & 2 & 1 & $\ldots$ & 2 \\
\hline
\end{tabular}

Setelah tabel DTM terbentuk, kemudian dilakukan perhitungan total frekuensi kata. Jika terdapat kata yang memiliki frekuensi kurang dari 3, maka kata tersebut dihilangkan. Kemudian hasil perhitungan disimpan pada tabel frekuensi kata. Contoh struktur tabel frekuensi kata dapat dilihat pada tabel 2.

Tabel 2 Tabel frekuensi kata

\begin{tabular}{ll}
\hline Kata & Frekuensi \\
\hline Kata 1 & 5 \\
Kata 2 & 10 \\
Kata ... & $\ldots$ \\
Kata n & 8 \\
\hline
\end{tabular}

Pada analisis sentimen dibutuhkan data latih agar dapat mengklasifikasikan tweet ke dalam kelas sentimen positif maupun negatif menggunakan algoritma NBC. Data latih didapatkan dari tabel frekuensi kemudian dilakukan perhitungan nilai ln probabilitas pada setiap kata dengan teknik additive smoothing untuk menghindari data dengan nilai frekuensi nol [4]. Rumus perhitungan ln probabilitas dapat dilihat pada persamaan (1).

$$
\ln p\left(w \mid C_{k}\right)=\ln \frac{f+1}{\sum_{w}\left(f_{w}+1\right)}
$$

Dimana:

$w:$ kata.

$\mathrm{Ck}$ : kelas (positif atau negatif).

$f$ : frekuensi kemunculan kata.

$f w$ : frekuensi kata pada data

latih.

Kemudian dilakukan klasifikasi terhadap tweet untuk menentukan kelasnya dengan cara menghitung nilai ln probabilitas untuk kelas sentimen positif dan sentimen negatif. Rumus perhitungan In probabilitas tiap kelas terhadap tweet yang diperoleh dapat dilihat pada persamaan (2). 


$$
\ln p\left(C_{k} \mid t\right)=\sum_{y} \ln P_{y}+\sum_{x} f_{x} * \ln \frac{1}{\Sigma_{w}\left(f_{w}+1\right)}
$$

Dimana:

$\mathrm{Ck}$ : kelas positif atau negatif.

$t$ : tweet.

$w:$ kata pada data latih.

$y$ : kata pada data uji yang terdapat pada data latih.

$x$ : kata pada data uji yang tidak terdapat pada data latih.

$\ln P y: \ln$ probabilitas dari kata yang terdapat pada data latih.

$f_{x}$ : frekuensi kata pada data uji yang tidak terdapat pada data latih.

$f w$ : frekuensi kata pada data latih.

Kemudian pada analisis faktor digunakan metode PCA yang dilakukan terhadap kata yang terdapat pada kelas positif dan negatif. Analisis faktor adalah teknik analisis yang bertujuan untuk menyederhanakan bentuk variabel yang memiliki korelasi tinggi menjadi sejumlah faktor yang berjumlah lebih sedikit daripada variabel yang ada [5].

Pada penelitian ini variabel adalah masing-masing frekuensi kata yang telah melalui tahap klasifikasi. Kemudian disusun dalam bentuk vektor dan dihitung vektor rata-ratanya. Selanjutnya dilakukan perhitungan untuk mendapatkan nilai selisish dari matriks vektor asal dengan matriks vektor ratarata. Kemudian dilakukan perhitungan untuk mencari matriks kovarian A dengan persamaan (3).

$$
A=Y^{T} \times Y
$$

Dimana:

$$
\begin{aligned}
& A: \text { matriks kovarian. } \\
& Y^{T}: \text { hasil transpos selisih matriks } \\
& \text { vektor asal dengan matriks } \\
& \quad \text { vektor rata-rata. } \\
& Y: \text { selisih matriks vektor asal dengan } \\
& \text { matriks vektor rata-rata. } \\
& \quad \text { Tahap berikutnya adalah }
\end{aligned}
$$
menghitung Eigen Value dan Eigen Vektor dari A yang kemudian hasilnya diurutkan mulai dari yang paling besar ke terkecil. Setelah itu dilakukan perhitungan untuk mencari nilai dari principal component dengan persamaan (4).

$$
P C=(Y \times v)
$$

Dimana:

$P C$ : Principal Component.

$Y$ : selisih matriks vektor asal dengan matriks vektor rata-rata.

$v$ : nilai Eigen Vektor.

Kemudian setiap kata yang memiliki korelasi tinggi dikelompokan menjadi suatu fakor. Jumlah faktor ditentukan hingga mendapatkan hasil pengelompokan kata yang sesuai. Jumlah data dan banyaknya frekuensi kata juga sangat berpengaruh pada hasil analisis faktor. Setelah faktor diinterpretasi, diperlukan validasi yang dilakukan oleh pakar.

4. Pengembangan Aplikasi

Aplikasi pada penelitian ini terdiri dari analisis sentimen, penambahan data latih, dan analisis faktor. Pada proses analisis sentimen diawali dengan pengambilan data baru berupa tweet menggunakan Twitter API. Total pengambilan tweet dan objek diproses sesuai masukan dari pengguna. Kemudian data tersebut diproses dengan menggunakan tahap preprocessing. Hasil dari data yang telah melalui tahap preprocessing kemudian dilakukan perhitungan nilai ln probabilitas untuk mengklasifikasikan setiap data ke dalam kelas sentimen positif atau negatif. Proses analisis sentimen dapat dilihat pada gambar 1.

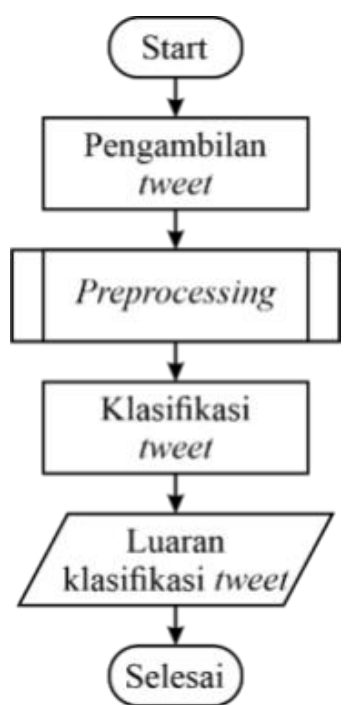

Gambar 1. Proses analisis sentimen 
Pada proses penambahan data latih administrator dapat mengubah atau menghapus data yang mengalami kesalahan pada proses klasifikasi. Ketika data sudah terklasifikasi dengan benar, data tersebut dapat ditambahkan sebagai data latih. Proses penambahan data latih dapat dilihat pada gambar 2 .

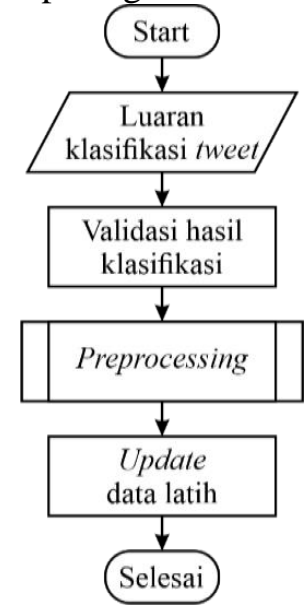

Gambar 2. Proses penambahan data latih Tahap analisis faktor dapat dilakukan secara langsung karena analisis faktor pada penelitian ini menggunakan data latih. Jumlah faktor dapat ditentukan oleh pengguna dan hasil pengelompokan ditampilkan berdasarkan jumlah faktor yang dimasukan. Jika hasil pengelompokan masih kurang sesuai, pengguna dapat mengubah masukan jumlah faktor hingga muncul hasil yang diinginkan. Proses ini dapat dilakukan dengan bantuan pakar untuk melakukan validasi dari faktor yang terbentuk. Proses analisis faktor dapat dilihat pada gambar 3.

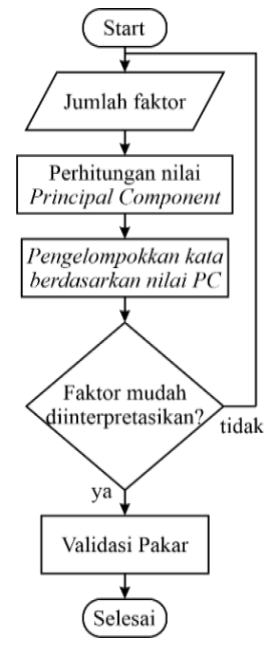

Gambar 3.Proses analisis faktor
5. Pengujian

Pengujian klasifikasi

menggunakan algoritma NBC pada penelitian ini dilakukan dengan cara pengambilan sampel dan melakukan perhitungan akurasi dari hasil klasifikasi dengan rumus seperti pada persamaan (5).

Dimana:

$$
\operatorname{Akurasi}(\%)=\frac{x}{v} \times 100 \%
$$

$x$ : total data uji yang masuk ke kelas yang benar.

$y$ : total keseluruhan data uji.

Pengujian juga dilakukan pada waktu komputasi. Perhitungan waktu dilakukan dengan cara mencari selisih waktu mulai dari proses dijalankan hingga proses tersebut selesai dengan sintaks pada Python.

\section{Simpulan Analisis Faktor}

Pada faktor yang terbentuk dari proses analisis faktor, dilakukan evaluasi variabel hasil dari perhitungan Principal Component dengan faktor yang terbentuk dari hasil wawancara atau diskusi dengan pakar kemudian ditarik sebuah kesimpulan.

\section{HASIL DAN PEMBAHASAN}

Beberapa penelitian terdahulu tentang penggunaan text mining dengan data yang diambil dari media sosial adalah sebagai berikut. Penerapan text mining untuk menganalisis sentimen masyarakat terhadap calon Presiden Indonesia 2014 menggunakan algoritma NBC yang datannya diambil dari Twitter [6]. Hasil dari penelitian tersebut berupa hasil klasifikasi sentimen ke dalam tiga kelas, yaitu sentimen positif, negatif, dan netral.

Penelitian analisis sentimen terhadap pemerintahan Joko Widodo [7] juga mengambil data melalui Twitter. Pada penelitian tersebut data yang diperoleh sebanyak 400 tweet yang terdiri dari 300 data latih dan 100 data uji. Penelitian tersebut menggunakan metode NBC untuk mengklasifikasi opini masyarakat terhadap pemerintahan Bapak Jokowi dengan hasil akurasi 97\%. Selain itu juga terdapat penelitian tentang penerapan text mining yang juga 
menggunakan algoritma NBC terhadap tokoh publik dan data diperoleh dari Twitter [8]. Pada penelitian tersebut dihasilkan perbandingan akurasi algoritma NBC menggunakan termfrequency dengan algoritma NBC menggunakan Term Frequency-Inverse Document Frequency (TF-IDF).

Kemudian terdapat penelitian penerapan text mining dan algoritma NBC pada tempat wisata dengan studi kasus Jawa Barat [9]. Data diperoleh dari komentar masyarakat di Google Maps. Penelitian tersebut menggunakan Convert Emoticon pada tahap preprocessing untuk membantu mendeskripsikan ekspresi masyarakat dalam suatu kalimat yang mengandung simbol emoticon. Pada penelitian ini diperoleh hasil klasifikasi sentimen positif dan negatif. Implementasi text mining tjuga dilakukan terhadap tempat wisata di Kota Malang [10]. Penelitian tersebut menggunakan algoritma NBC dan seleksi fitur Query Expansion Ranking untuk melakukan klasifikasi sentimen. Hasil uji terbaik dengan akurasi $86.6 \%$ pada penelitian tersebut adalah dengan rasio seleksi fitur $75 \%$.

Penelitian menggunakan algoritma NBC juga telah dilakukan terhadap suatu brand Smartfren [11]. Pada penelitian tersebut data didapatkan dari situs import.io sebanyak 7388 kalimat opini masyarakat terhadap merek Smartfren. Data latih yang digunakan sebanyak 1000 data dan data uji menggunakan 6388 data. Penelitian tersebut juga menghasilkan klasifikasi sentimen positif dan negatif.

Penelitian menggunakan text mining juga telah diterapkan pada opini masyarakat tentang hotel [12]. Penelitian terebut menggunakan algoritma Support Vector Machine (SVM) berbasis Particle Swarm Optimization. Data yang digunakan terdiri 300 data yang diambil dari situs www.tripadvisor.com. Penelitian tersebut dilakukan hingga tahap klasifikasi sentimen positif dan negatif masyarakat.

Penerapan text mining juga dilakukan untuk analisis sentimen digunakan untuk mengetahui tingkat kepuasan pengguna penyedia jasa layanan telekomunikasi seluler di Indonesia [13]. Data pada penelitian tersebut diperoleh dari Twitter dan diolah menggunakan metode SVM dengan menggunakan Lexcion Based Features. Penelitian tersebut dilakukan hanya sampai pada tahap klasifikasi jenis sentimen dan perbandingan akurasi antara metode Support Vector Machine menggunakan Lexcion Based Features dengan Support Vector Machine tanpa Lexcion Based Features.

Analisis sentimen masyarakat terhadap sebuah film [14] juga termasuk penggunaan text mining. Data pada penelitian tersebut diperoleh dari Twitter sebanyak 3000 tweet. Pada penelitian tersebut dihasilkan klasifikasi sentimen ke dalam kelas sentimen positif, negatif dan netral menggunakan algoritma SVM.

Implementasi text mining juga telah dikombinasikan dengan metode $\mathrm{K}$ Means Clustering untuk automasi penentuan tren topik Skripsi [15]. Uji coba pada penelitian tersebut diperoleh hasil yang baik dengan $89 \%$ responden menyetujui tren topik skripsi pada aplikasi yang dibuat.

Pada penelitian yang dilakukan, diperoleh hasil pengelompokan data latih sebagai berikut.

- Data latih positif dengan objek 'Grab' sebanyak 260 tweet.

- Data latih negatif dengan objek 'Grab' sebanyak 337 tweet.

- Data latih positif dengan objek 'Gojek' sebanyak 959 tweet.

- Data latih negatif dengan objek 'Gojek' sebanyak 1290 tweet.

- Selain data latih, juga terdapat hasil pengelompokan data uji sebagai berikut.

- Data uji positif dengan objek 'Grab' sebanyak 66 tweet.

- Data uji negatif dengan objek 'Grab' sebanyak 86 tweet.

- Data uji positif dengan objek 'Gojek' sebanyak 241 tweet.

- Data uji negatif dengan objek 'Gojek' sebanyak 324 tweet. 
Pada hasil analisis sentimen terdiri dari hasil text mining dan hasil klasifikasi tweet menggunakan algoritma NBC. Pada proses text mining sistem telah berhasil mengambil data berupa tweet dengan objek dan jumlah yang dimasukan oleh pengguna. Data yang telah diambil kemudian dilakukan tahap preprocessing. Pada tahap preprocessing data telah berhasil dibuah menjadi huruf kecil secara keseluruhan, link dan mention pada data serta karakter yang bukan huruf telah dihilangkan, kata pada data yang terdapat pada stopword telah dihapus, dan kalimat telah terpisah menurut kata yang menyusunnya. Kata penyusun kalimat tersebut juga telah berhasil diubah menjadi kata dasar.

Pada proses klasifikasi sistem telah berhasil melakukan perhitungan $\mathrm{ln}$ probabilitas setiap kata dalam data uji dengan kata yang ada pada model probabilitas data latih. Dari hasil klasifikasi tersebut, masih terdapat data yang belum terklasifikasi dengan benar sehingga diperlukan threshold. Nilai threshold diperoleh dari beberapa kali percobaan hingga menemukan nilai yang sesuai yaitu 1,1. Tabel 3 merupakan percobaan nilai threshold untuk melakukan klasifikasi terhadap 717 data.

Tabel 3 Percobaan nilai threshold

\begin{tabular}{lc}
\hline Threshold & $\begin{array}{c}\text { Hasil klasifikasi } \\
\text { yang benar }\end{array}$ \\
\hline 1 & 501 tivet \\
1,1 & 502 tivet \\
1,2 & 498 tivet \\
\hline \multicolumn{2}{c}{ Pada proses analisis faktor }
\end{tabular}
diperoleh hasil 6 faktor positif dan 5 faktor negatif pada Grab, sedangkan pada Gojek diperoleh 8 faktor positif dan 6 faktor negatif. Berikut adalah hasil analisis faktor pada Grab dan Gojek.

1. Faktor positif Grab adalah Promo Grabfood, kesan pengemudi Grab, pelayanan dari Grab, layanan sarana transportasi Grab yang bisa diandalkan, kepuasan konsumen, dan fitur dari layanan Grab.

2. Faktor negatif Grab adalah ketidakpuasan konsumen Grab, sifat menyebalkan oknum pengemudi Grab, harga yang mahal, esan negatif konsumen terhadap Grab, dan pelayanan yang buruk.

3. Faktor positif Gojek adalah pelayanan Gojek yang baik, cepatnya respon dari Gojek, perjuangan mitra Gojek, layanan Gosend, layanan Gofood, kepuasan konsumen Gojek, peluang berkembang bagi Gojek, dan aplikasi yang mudah.

4. Faktor negatif Gojek adalah permaslahan aplikasi, kekecewaan konsumen Gojek, kualitas costumer service Gojek, keluhan konsumen, penipuan yang terjadi, dan permasalahan transaksi.

Kemudian terdapat hasil uji coba meliputi uji coba akurasi klasifikasi, uji coba analisis faktor, dan uji coba waktu komputasi. Uji akurasi klasifikasi dilakukan terhadap 717 data uji yang terdiri dari 152 data uji Grab dan 565 data uji Gojek. Data uji tersebut telah diklasifikasikan ke dalam kelas sentimen positif dan negatif secara manual. Pengujian dilakukan untuk mengetahui perbandingan data yang diklasifikasikan dengan benar dan data yang salah dalam tahap klasifikasi.

Pada proses perhitungan akurasi objek Grab didapatkan bahwa sebanyak 113 tweet dari 152 tweet berhasil diklasifikasikan secara benar. Pada objek Gojek sebanyak 389 tweet dari 565 tweet berhasil diklasifikasikan secara benar. Kemudian diakukan perhitungan untuk mencari total akurasi keseluruhan dengan menjumlahkan banyak tweet yang benar dibagi dengan total keseluruhan tweet. Perhitungan akurasi klasifikasi menggunakan persamaan (5). Perhitungan akurasi klasifikasi adalah sebagai berikut.

$$
\begin{aligned}
\text { Akurasi Grab } & =\frac{113}{152} \times 100 \%=74,34 \% \\
\text { Akurasi Gojek } & =\frac{389}{565} \times 100 \%=68,84 \% \\
\text { Akuresi rata }- \text { rata } & =\frac{74.34+68.84}{2} \times 100 \%=71.59 \%
\end{aligned}
$$

Hasil akurasi merupakan nilai yang menunjukan presentase keberhasilan aplikasi dalam melakukan klasifikasi. Total akurasi rata-rata yang diperoleh dalam melakukan klasifikasi kedua objek 
adalah $71,59 \%$ dengan nilai akurasi 74,34\% pada data uji Grab dan $68,84 \%$ pada data uji Gojek.

Kemudian terdapat hasil uji coba waktu komputasi. Uji waktu komputasi dilakukan pada masing-masing tahapan yang ada pada aplikasi analisis sentimen. Pengujian pada tahap preprocessing dan tahap klasifikasi dilakukan sebanyak tiga kali kemudian dihitung rata-rata waktunya. Pengujian waktu pada tahap preprocessing dan tahap klasifikasi dilakukan pada data uji pada objek Grab positif sebanyak 22 data yang berbeda tiap kali pengujian. Pada uji komputasi analisis faktor menggunakan data latih sebanyak 2846 data. Hasil rata-rata pengujian waktu komputasi dapat dilihat pada tabel 4 .

Tabel 4 Uji komputasi

\begin{tabular}{c|lc}
\hline \multicolumn{2}{|c}{ Tabel 4 Ujl komputasi } \\
\hline No & \multicolumn{1}{|c}{ Proses } & Waktu \\
\hline 1. & Preprocessing & $\pm 14,25$ detik \\
2. & Klasifilasi & $\pm 0,2$ detik \\
3. & Analisis Falktor & $\pm 6,53$ detik \\
\hline
\end{tabular}

Berdasarkan penelitian yang ada, total waktu respon sebuah web dapat dikategorikan menjadi 3, yaitu respon yang instan dengan lama waktu 0.1 detik, respon yang cukup dengan lama waktu 1 detik, dan respon yang lambat dengan lama waktu 10 detik. Pada tabel 4 diketahui bahwa pada tahap preprocessing memerlukan waktu yang paling lama dari keseluruhan proses yaitu 14,25 detik atau sekitar 0,64 detik setiap tweet. Perolehan waktu ini belum efisien karena semakin banyak tweet yang diambil akan semakin panjang waktu untuk melakukan tahap preprocessing. Pada tahap klasifikasi hanya memerlukan waktu 0,2 detik untuk melakukan proses pada 22 tweet. Pada tahap analisis faktor dapat dikatakan sudah efisien karena hanya memerlukan waktu hanya 0,002 detik setiap tweet.

\section{SIMPULAN}

Aplikasi untuk melakukan analisis opini masyarakat terhadap keunggulan dan kekurangan dari layanan Gojek dan Grab dengan implementasi text mining menggunakan algoritma Naïve Bayes Classifier dan analisis faktor telah berhasil dibuat. Berdasarkan hasil penelitian dan uji coba yang telah dilakukan dapat disimpulkan sebagai berikut.

1. Aplikasi yang dibuat dapat Aplikasi yang dibuat dapat mengumpulkan data terbaru secara real time.

2. Tahap preprocessing pada aplikasi dapat berjalan dengan baik pada tweet yang memiliki tatanan bahasa Indonesia yang sesuai dengan ejaan yang disempurnakan (EyD), namun dalam prosesnya membutuhkan waktu yang cukup lama.

3. Seleksi fitur yang digunakan untuk menghapus jumlah kata yang kurang dari tiga berjalan dengan baik.

4. Algoritma Naïve Bayes Classifier pada aplikasi ini menghasilkan akurasi pada objek Grab 74,34\%, pada objek Gojek 68,84\% dan akurasi rata-rata dari kedua objek tersebut sebesar $71,59 \%$.

5. Metode Principal Component Analysis dapat mengelompokkan kata ke dalam beberapa faktor. Pada Grab diperoleh 6 faktor positif dan 5 faktor negatif, sedangkan pada Gojek diperoleh 8 faktor positif dan 6 faktor negatif. Setiap faktor yang diperoleh dilakukan interpretasi dan kemudian dilakukan validasi oleh pakar.

\section{SARAN}

Berdasarkan hasil penelitian dan uji coba yang telah dilakukan, saran bagi pengembang aplikasi selanjutnya adalah menambahkan data latih untuk menyeimbangkan data antara sentimen positif dan sentimen negatif agar dapat meningkatkan hasil akurasi pada proses klasifikasi sentimen.

\section{DAFTAR PUSTAKA}

[1] Carr, C.T. dan Hayes, R.A. 2015, Social Media: Defining, Developing, and Divining, Atlantic Journal of Communication, 23:4665.

[2] Nugroho, D.G., Chrisnanto, Y.H. dan Wahana, A. 2016, 'Analisis 
Sentimen Pada Jasa Ojek Online Menggunakan Metode Naive Bayes', prosiding SNST ke-7, Semarang, hal. 156-161.

[3] Muljono, Artanti, D.P., Syukur, A., Prihandono, A. dan Setiadi, D.R.I.M. 2018, 'Analisa Sentimen untuk Penilaian Pelayanan Situs Belanja Online Menggunakan Algoritma Naïve Bayes' seminar KNSI 2018, Semarang, hal. 165170.

[4] Amora, R., dan Fauzy, A. 2016, 'Implementasi Metode Naïve Bayes Dalam Mendiagnosis Penyakit Demam Dengue dan Demam Berdarah Dengue (Studi kasus: RSUD R. Syamsudin, SH Kota Sukabumi)', prosiding SNIPS 2016, Yogyakarta, hal. 646-655.

[5] Ameriksa, S. \& Nurhidayah, 2014, Analisis Faktor-Faktor yang Mempengaruhi Kinerja Kemitraan Bisnis PT PLN. Jurnal Manajemen dan Akuntansi, 3:1-14.

[6] Nurhuda, F., Sihwi, S.W. dan Doewes, A. 2013, Analisis Sentimen Masyarakat terhadap Calon Presiden Indonesia 2014 berdasarkan Opini dari Twitter Menggunakan Metode Naïve Bayes Classifier, Jurnal ITSMART, 2:3542.

[7] Mahardhika, Y.S. dan Zuliarso, E. 2018, 'Analisis Sentimen Terhadap Pemerintahan Joko Widodo pada Media Sosial Twitter Menggunakan Algoritma Naïve Bayes Classifier', prosiding SINTAK 2018, Semarang, hal. 409-413.

[8] Hidayatullah, A.F. dan Azhari, S.N. 2014, 'Analisis Sentimen dan Klasifikasi Kategori Terhadap Tokoh Publik pada Twitter', dipresentasikan pada Seminar Nasional Informatika di Yogyakarta, 12 Agustus.

[9] Wilianto, L., Pudjiantoro, T.H. dan Umbara, F.R. 2017, 'Analisis Sentimen terhadap Tempat Wisata dari Komentar Pengunjung dengan Menggunakan Metode Naive Bayes Classifier Studi Kasus Jawa Barat', prosiding SNATIF Ke -4, Cimahi, hal. 439-448.

[10] Fanissa, S., Fauzi, M.A. dan Adinugroho, S. 2018, Analisis Sentimen Pariwisata di Kota Malang Menggunakan Metode Naive Bayes dan Seleksi Fitur Query Expansion Ranking, Jurnal Pengembangan Teknologi Informasi dan Ilmu Komputer, 2:2766-2770.

[11] Zuhri, F.N. dan Alamsyah, A. 2017, 'Analisis Sentimen Masyarakat Terhadap Brand Smartfren Menggunakan Naïve Bayes Classifier di Forum Kaskus', prosiding Management Volume 4, Bandung, hal. 242-251.

[12] Indrayuni, E. 2016, Analisa Sentimen Review Hotel Menggunakan Algoritma Support Vector Machine Berbasis Particle Swarm Optimization, Jurnal Evolusi, 4:20-27.

[13] Rofiqoh, U., Perdana, R.S. dan Fauzi, M.A. 2017, Analisis Sentimen Tingkat Kepuasan Pengguna Penyedia Layanan Telekomunikasi Seluler Indonesia Pada Twitter Dengan Metode Support Vector Machine dan Lexicon Based Features, Jurnal Pengembangan Teknologi Informasi dan Ilmu Komputer, 1:1725-1732.

[14] Rahutomo, F., Saputra, P.Y. dan Fidyawan, M.A. 2018, Implementasi Twitter Sentiment Analysis untuk Review Film Menggunakan Algoritma Support Vector Machine, Jurnal Informatika Polinema, 4:93-100.

[15] Prilianti, K. R. dan Wijaya, H. 2014. Aplikasi Text Mining untuk Automasi Penentuan Tren Topik Skripsi dengan Metode K-Means Clustering, Jurnal Cybermatika, 2:1-6 